\title{
TEORIA E PRÁTICA ASSISTENCIAL NA ENFERMAGEM: O ENSINO E O MERCADO DE TRABALHO*
}

Rosa Maria Rodrigues**

Maria Lúcia Zanetti***

RODRIGUES, R.M.; ZANETTI, M.L. Teoria e prática assistencial na enfermagem: o ensino e o mercado de trabalho.

Rev.latino-am.enfermagem, Ribeirão Preto, v. 8, n. 6, p. 102-109, dezembro 2000.

Este estudo identifica como os enfermeiros docentes e assistenciais vivenciam a relação entre o ensino e o mercado de trabalho na enfermagem. Os dados foram coletados mediante a realização de entrevistas e de análise de documentos. Na análise utilizamos categorias metodológicas e de conteúdo. Evidenciamos que o ensino está distante da prática assistencial pautando-se em conteúdos que nela não encontram correspondência; existe uma defasagem entre o que se ensina na graduação e a incorporação de novas tecnologias, práticas e saberes. Aponta-se a retomada das reflexões sobre o ensino da enfermagem a fim de aproximar o espaço de ensino e o trabalho assistencial.

\section{UNITERMOS: enfermagem, ensino, trabalho}

\section{INTRODUÇÃO}

Em nosso envolvimento com a prática da enfermagem deparamo-nos com situações que mostram que o ensino de graduação em enfermagem tem dificuldades para adequar-se às exigências do mercado de trabalho.

Ao delimitarmos a problemática do presente estudo, resgatando as alterações curriculares que aconteceram na enfermagem brasileira, percebemos que uma tônica perpassou os discursos quando das propostas de alterações nos currículos dando conta que o ensino/ educação do enfermeiro está distante da prática profissional, sendo esta uma das afirmações tomadas para justificar aquelas alterações. Observamos que, apesar daquele esforço por adequar-se às exigências do mercado, isso não acontecia, quando surgiam propostas de novas alterações para darem conta da aproximação ao mercado de trabalho.

Partindo da suposição de que a escola tem dificuldades para preparar o trabalhador-enfermeiro para o mercado de trabalho, fazemos algumas interrogações.
Cabe à escola apenas adaptar-se ao mercado de trabalho? Em que medida o mercado de trabalho reflete as necessidades de saúde da maioria das pessoas? Qual concepção de escola/educação está implícita quando defendemos que a escola deve adequar-se ao mercado de trabalho? Por outro lado, quais são as reais possibilidades de transformação a partir do espaço de ensino? Para responder estas questões pretendemos estudar a relação entre o ensino e o mercado de trabalho na enfermagem identificando como os enfermeiros docentes e assistenciais vivenciam e enfrentam a relação entre $o$ ensino e a atividade assistencial a fim de fornecer elementos para a reflexão acerca da formação profissional, sendo este o objetivo do estudo.

\section{APONTAMENTOS METODOLÓGICOS}

Realizamos a coleta de dados na cidade de Cascavel, Região Oeste do Estado do Paraná, nos meses de agosto e setembro de 1999, em três espaços diferentes que, de acordo com a realidade estudada, constituíam-se

\footnotetext{
* Estudo realizado como parte dos requisitos para obtenção do título de Mestre em Enfermagem do Programa de Mestrado em Enfermagem Fundamental da Escola de Enfermagem de Ribeirão Preto da Universidade de São Paulo em convênio com a Secretaria de Ciência e Tecnologia do Estado do Paraná na modalidade de Mestrado interinstitucional

** Enfermeira Especialista em Saúde Pública, Professora do Curso de Enfermagem da UNIOESTE/Campus de Cascavel, mestranda do Programa de Mestrado em Enfermagem Fundamental da Escola de Enfermagem de Ribeirão Preto da Universidade de São Paulo

*** Professor Doutor junto ao Departamento de Enfermagem Geral e Especializada da Escola de Enfermagem de Ribeirão Preto da Universidade de São Paulo. Endereço: Av. Bandeirantes, 3900 - Monte Alegre - 14040-902 - Ribeirão Preto - São Paulo Brasil.E-mail: zanetti@glete.eerp.usp.br
} 
nos principais locais de atuação do enfermeiro. Desta maneira, realizamos 12 entrevistas com enfermeirosdocentes de uma instituição de ensino de graduação em enfermagem. Nesse espaço selecionamos os docentes que fossem enfermeiros, que tivessem regime de trabalho de 40 horas, dedicação exclusiva à Universidade e que não fizessem parte do grupo de enfermeiros que realizavam pós-graduação, nível mestrado, na modalidade de mestrado interinstitucional. Realizamos seis entrevistas com enfermeiros de uma instituição hospitalar, que contava com 28 enfermeiros. Os seis enfermeiros foram inseridos conforme a disponibilidade e interesse em aderir ao estudo, uma vez que havia uma certa sobrecarga de contatos para atividades de investigação junto aos mesmos. Realizamos ainda, sete entrevistas com enfermeiros de uma instituição de saúde pública. Nessa instituição havia 43 enfermeiros, desses, 26 estavam atuando nas Unidades Básicas de Saúde. Assim, desses vinte e seis enfermeiros sorteamos sete. As entrevistas continham questões fechadas (identificação) e abertas. As questões abertas foram as seguintes para os enfermeiros docentes: Fale-nos como você tem percebido e vivenciado a relação entre a formação acadêmica do aluno de enfermagem e as exigências do mercado de trabalho? O que você considera mais divergente entre o que se ensina no espaço acadêmico e o que se faz efetivamente no espaço de trabalho assistencial? A que você atribuiria essas divergências e como poderiam ser superadas? Para os enfermeiros assistenciais fizemos as seguintes questões: Como foi o seu processo de inserção no mercado de trabalho? Se houve dificuldades apontenos quais e a que você as atribuiria? Como você avalia a relação entre o que você aprendeu no curso universitário de enfermagem e as exigências da instituição onde você trabalha? Como você acha que poderiam ser superadas essas dificuldades? As entrevistas foram gravadas e transcritas.

O projeto de pesquisa passou pela avaliação do Comitê de Ética em Pesquisas da Escola de Enfermagem de Ribeirão Preto, conforme preconizado pela Resolução 196/96 do Conselho Nacional de Saúde sobre a pesquisa envolvendo seres humanos. Todos os sujeitos leram o termo de consentimento e deram o seu aceite à participação na pesquisa. Além dos dados obtidos através das entrevistas, utilizamo-nos de documentos sobre o ensino de enfermagem, especialmente os Pareceres 163/ 72, 314/94 e Resolução 04/72 e de programas de ensino do curso de graduação em que graduaram-se a maioria dos entrevistados.

Delimitamos, para orientar a investigação, categorias metodológicas e de conteúdo. As categorias metodológicas são as que embasam a relação pesquisador/ objeto e iluminam todos os procedimentos da pesquisa. Permitem que o pesquisador mantenha coerência entre o método (dialético) e os procedimentos necessários para a execução da pesquisa. Conforme KUENZER (1998) permitem investigar qualquer objeto em qualquer realidade dado corresponderem à leis objetivas e, portanto universais. Orientaram a investigação as categorias metodológicas práxis, totalidade, mediação.

O objeto precisa ser tomado na sua especificidade e relação com outros objetos e com a totalidade (KUENZER, 1998). A apreensão do objeto na sua especificidade/particularidade, se faz possível através das categorias de conteúdo. Em nosso estudo utilizamos as seguintes categorias de conteúdo: mercado de trabalho, modo de produção, divisão do trabalho, ensino/educação. Utilizamo-nos das propostas de KUENZER (1998) e CURY (1987), para a definição e descrição destas categorias.

\section{CARACTERIZAÇÃO DOS ENTREVISTADOS}

Dos 25 entrevistados apenas dois eram do sexo masculino. Dos doze enfermeiros docentes dois graduaram-se na década de 70 e dez na década de oitenta. Sete deles cursaram graduação na Universidade Estadual do Oeste do Paraná e cinco em outras escolas no Estado de São Paulo, Santa Catarina e Rio de Janeiro. Já os enfermeiros assistenciais, graduaram-se na Universidade Estadual do Oeste do Paraná, apesar de não ter sido este um critério de inclusão no estudo. Cinco deles concluíram a graduação na década de oitenta, e oito na década de noventa. Quanto à inserção na pós-graduação, constatamos que os enfermeiros docentes apresentam maior envolvimento, sendo que apenas um não tinha curso de pós-graduação e os demais eram especialistas (12), mestres (04) e doutor (01). Já entre os enfermeiros assistenciais apenas cinco cursaram pós-graduação (especialização), e os oito restante não tinham nenhum curso de pós-graduação. Chama a atenção ainda a questão salarial, em que a maior parte dos enfermeiros docentes recebe entre $\mathrm{R} \$ 900,00$ e $\mathrm{R} \$ 1.500,00$ com um emprego e a maior parte dos assistenciais recebem entre $R \$ 600,00$ e R $\$ 800,00$ sendo que ultrapassam esse valor aqueles que têm mais de um emprego.

As elaborações feitas a partir das falas dos sujeitos nas quais a relação entre o ensino e o mercado de trabalho pode ser evidenciada nos aspectos seguintes, que passamos a discutir. 
A MANIFESTAÇÃO DA DIVISÃO DO TRABALHO NAQUILO QUE É ENSINADO NA GRADUAÇÃO E AS EXIGÊNCIAS DO MERCADO DE TRABALHO

A divisão do trabalho apresenta-se evidente nas falas de enfermeiros docentes, quando relatam que a escola prepara o enfermeiro para prestar assistência e que o mercado espera dele administração e gerência, como podemos observar nas seguintes falas:

“(...) esperavam uma enfermeira administrativa e eu fui formada para a assistência (...)". EnD E2

“(...) a gente prepara ele para ser um enfermeiro assistencialista pra trabalhar com a comunidade e o que acontece não é isso. Ele trabalha com a parte administrativa, burocrática (...)". EnD E5

Considerando que a administração em enfermagem faz parte dos currículos desde 1962 (CARVALHO,1972), indagamos quais as razões desta referência, segundo a qual, o mercado espera um enfermeiro-administrador embora ele seja formado para a assistência, não conseguindo, portanto, desenvolver a contento a função gerencial.

Os aspectos referentes a esta questão que devem ser considerados são: qual o modelo de enfermeirogerente exigido pelo mercado de trabalho e qual o modelo de enfermeiro-gerente preconizado pela escola. $\mathrm{O}$ que significa exercer a função administrativa na enfermagem? Parece-nos que estas indagações não podem ser compreendidas sem antes considerarmos o real espaço administrativo ocupado pelo enfermeiro.

$\mathrm{Na}$ organização do trabalho em saúde, em que predomina a divisão do trabalho, coube historicamente ao enfermeiro abarcar faces do trabalho da enfermagem que lhe conferem um status de trabalho intelectual. Contudo, esse trabalho não é autônomo, sua intelectualidade está submetida a fazer funcionar o trabalho da enfermagem e o da saúde. Dada sua submissão, não consegue gerir objetivos da própria enfermagem e sim objetivos impostos externamente, na maioria das vezes, alheios ao preconizado como ideal, tanto pela escola como pelos organismos competentes.

Segundo FRIGGOTTO (1999), a figura do gerente aparece num contexto em que, dada as transformações na forma de acumulação capitalista, a demanda por esse tipo gerencial torna-se um imperativo para o prosseguimento do processo de acumulação.

A função gerencial, por ser exercida por um nãoproprietário, pode levar à conclusão que o gerente possa exercer tal função baseada apenas em princípios técnicos e norteada por critérios dignos e justos o que, em função da vinculação do gerente aos objetivos da instituição, torna-se problemático.

A função gerencial, assim compreendida, pode constituir-se no encaminhamento que se dá ao ensino, voltado para "objetivos dignos", visto como capaz de propiciar a formação de um gerente competente para o mercado de trabalho. Nesta perspectiva, esquecemo-nos do real espaço do gerente no modo capitalista de produção, considerando possível tanto a prática administrativa neutra como a prática da enfermagem. Contudo, pensamos que condições concretas como a questão salarial, por exemplo, aproximam-nos dos demais trabalhadores da enfermagem considerados manuais e, nesse sentido, cremos que o enfermeiro deve rever essa sua postura de gerir apenas objetivos institucionais.

Um outro aspecto mais específico ao ensino é o referente aos conteúdos ministrados na escola, e aqui tomamos como referência os conteúdos da disciplina de "Administração", a mais citada pelos enfermeiros quando referiam-se à distância entre o que é ensinado na escola e as exigências do mercado de trabalho. Buscando concretizar a afirmação de que os conteúdos do ensino podem estar deslocados da prática assistencial, analisamos o programa de estágio da disciplina de "Administração Aplicada à Enfermagem", vigente de 1987 a 1992 na instituição de ensino estudada. O programa em questão preconiza como ações administrativas do enfermeiro desde a coordenação do trabalho da equipe de enfermagem, atividades assistenciais, manutenção e controle das unidades, seja no que se refere à segurança, espaço físico, previsão e provisão de recursos materiais e humanos, até a sistematização da assistência. Estabelece que o aluno deverá aplicar o processo de enfermagem a pacientes graves e realizar a prescrição da assistência de enfermagem. Na prática assistencial, até o momento, a organização da assistência não está baseada na sistematização preconizada pelo processo de enfermagem, o que nos permite afirmar que isto se constitui em um bom exemplo da distância que existe entre aquilo que é prioridade na formação e o que o aluno irá enfrentar, posteriormente.

Diante disso, é possível compreendermos porque os profissionais entrevistados referiram que a administração que aprenderam não era a mesma que encontraram depois de formados. Nesse aspecto podemos perceber uma situação conflituosa, pois como dissemos anteriormente, dado à vinculação do enfermeiro ao fazer funcionar a instituição, ele gerencia objetivos alheios à assistência de enfermagem. Então, o problema não estaria no ensino e sim nas instituições empregadoras, e aí é que deveriam haver mudanças. Concordamos que esta questão é presente e que o caminho não seria formar apenas para atender às exigências gerenciais das instituições; 
entendemos que a escola é também um espaço de discussão da prática e não da simples aceitação.

Um outro ângulo a ser considerado refere-se ao tipo de saber a ser repassado aos trabalhadores, conforme a classe a que pertencem, e o papel que desempenharão na organização coletiva do trabalho. Nesse ponto concordamos com KUENZER (1991) quando diz que, em se tratando da forma diferenciada com que os trabalhadores se apropriam do saber sobre o trabalho, em função do caráter excludente da educação brasileira, o grupo que conseguir permanecer na escola apropriarse-á do saber sobre o trabalho no seu interior, recebendo uma certificação que lhes permitirá ocupar, na hierarquia do trabalhador coletivo, o exercício das funções intelectuais; são os técnicos de nível médio e os profissionais de nivel superior (KUENZER, 1991, p.14). Os enfermeiros, sem dúvida, pertencem a esse grupo e, portanto, irão desempenhar o papel de intelectuais.

Dessa forma, a escola não estaria alheia ao mercado, mas cumprindo o seu papel de formar profissionais adequados às exigências do modo de produção capitalista, ou seja, enfermeiros que dominem os elementos teóricos da prática assistencial, embora nem sempre dominando ou nem sempre muito próximos da prática assistencial concreta. Nesse aspecto o enfermeiro teria que dominar os elementos teóricos do trabalho para poder gerir a assistência, contribuindo com a forma de organização do trabalho na forma capitalista de produção.

\section{O ENSINO DE ENFERMAGEM: O IDEALISMO PERPASSANDO OS CONTEÚDOS}

Os enfermeiros docentes e assistenciais mencionaram que o ensino focaliza-se em conteúdos "ideais" que não encontram correspondência na prática assistencial. Para explicitar esta referência, transcrevemos algumas falas que retratam o caráter idealizado do ensino.

“(...) é muito bonito você ver no livro como é que faz determinado procedimento mas quando você chega lá não tem nada daquilo que você aprendeu(...)". EnA E9

"Nós aprendemos a técnica (...) que as coisas deveriam ser da maneira correta (...) mas quando você sai da universidade, vários pontos são muito diferentes, muito desiguais do que você aprendeu (...) ". EnA10

"A gente aprende muita coisa ilusória (...) que você vai Ter que rever e na prática não funciona". EnA-3

“(...) Enquanto na escola você se preocupa

(...) de sistematizar a assistência (...) ai quando ele vai para o mercado de trabalho

o enfoque maior é na escala de trabalho

(...)". EnD-5

Nestas falas podemos perceber que a técnica ensinada aparece como um elemento importante na distância entre o que é ensinado e o que o profissional encontra efetivamente. Há uma exigência do cumprimento do saber técnico, de forma até rígida, durante a graduação e que, nem sempre é possível de ser seguido na vida profissional. A questão do repasse do saber técnico, já foi bastante estudada por ALMEIDA \& ROCHA (1989) denunciando a rigidez com é ensinado. Pensamos que o saber, apesar de técnico, comporta elementos ideológicos e políticos, e concordamos com ALMEIDA \& ROCHA (1989) ao discutirem o caráter disciplinar que carrega o repasse dos conteúdos técnicos.

Para os autores, a rigidez na execução das técnicas de enfermagem ligou-se ao projeto administrativo hospitalar de controle da força de trabalho; controle este realizado por enfermeiras, na manutenção das relações de poder no espaço hospitalar. (ibidem, p.51).

$\mathrm{O}$ ensino rígido de um saber técnico prende-se muito mais à exigência de manter-se o status da técnica e do conhecimento do que atender às necessidades concretas que o trabalho do enfermeiro exige. O elemento disciplinador, implícito na técnica, tem a finalidade de educar o enfermeiro para a aceitação das relações que irá enfrentar posteriormente.

Não estamos postulando que se abandonem as técnicas; pelo contrário, são elementos essenciais construídos pelo conjunto dos que exercem a enfermagem ao longo de toda a sua história. Elas fazem parte do que é específico à prática da enfermagem e não é deixando de ensiná-las que vamos melhorar a formação do enfermeiro. Questionamos, entretanto, a forma como são ensinadas e sua reprodução rígida, preparando o trabalhador-enfermeiro para que aceite as imposições que lhe serão feitas, posteriormente, no ambiente de trabalho. Ao deixarmos de ministrar o conteúdo técnico do ensino, abriríamos uma lacuna na formação profissional que inviabilizaria a inserção do enfermeiro no processo de trabalho da enfermagem. Essa necessidade não justifica, contudo, que este ensino prepare o profissional para a aceitação de relações de trabalho opressivas. Pelo contrário, ele deve dar ao profissional, instrumentos que o façam sentir-se parte do trabalho e que o capacitem a lutar pelos seus direitos e pelos direitos de quem é assistido.

Individualmente, constitui-se ainda em instrumento de negociação, uma vez que a força de trabalho melhor preparada pode inserir-se com maior facilidade no mercado de trabalho e ao comprovar isso, tem maior poder de barganha. Embora saibamos que a 
capacitação não é o principal requisito para ocupação dos melhores postos de trabalho, a desqualificação do trabalhador, através do esvaziamento dos conteúdos do ensino, no caso dos conteúdos técnicos, em nada contribuirá para a sua inserção no mercado de trabalho.

Além da técnica, o aspecto ideal do ensino tem uma outra face. Trata-se da concepção de educação e conhecimento, implícitos na idealização do ensino. Neste particular, concebemos a educação como auto-suficiente na produção de conhecimentos que devem ser repassados à prática para transformá-la; ou seja, a "teoria" produzida na escola é que carrega as verdades que devem ser absorvidas pela "prática". De certo modo, isto é um equívoco, dado que a escola é parte da superestrutura, é um produto da sociedade, não tendo, portanto, possibilidade de transformação exclusivamente a partir de suas elaborações.

Para KUENZER (1991), o saber é produzido pelos homens no conjunto das relações sociais, através do trabalho, por meio do qual eles adquirem o necessário para a sua sobrevivência. Porém, em função da divisão entre as classes sociais, o saber sobre o trabalho é apropriado de forma privada, e não por coincidência, pela classe que detém os meios de produção. Para a autora, mesmo existindo nas relações sociais, o saber é elaborado pela classe dominante que o utiliza em seu favor.

Ao ser apropriado, o saber será distribuído conforme a classe a que o indivíduo pertença e o papel que ele irá desempenhar na sociedade. Para a autora, aos filhos da classe trabalhadora é destinado um saber sem fundamentação, aprendido no fazer, e àqueles que irão dominar o processo de trabalho são repassados o seu conteúdo e os princípios teórico-metodológicos que o fundamentam. Porém, como registrado anteriormente, ao discutirmos o conteúdo de Administração, essa teoria deslocou-se da prática, acontecendo uma ruptura entre teoria e prática.

É no trabalho que podemos fazer a síntese entre teoria e prática. Porém, não podemos nos esquecer que o trabalho, sob a forma capitalista de produção, encontrase fragmentado. Nele há a ruptura entre teoria e prática, decisão e ação, trabalho intelectual e trabalho manual. (...) É a partir dessa ruptura que a consciência passa a supor-se como separada e superior à prática; é a partir deste momento que o trabalho intelectual se separa do manual, sobrepondo-se à realidade, emancipando-se do mundo, reificando-se (ibidem p.24-5).

Questionamo-nos se a teoria a que os sujeitos se referem não estaria relacionada à valorização e repasse de conteúdos através de instrumentos, não vinculados ao mundo do trabalho, onde o enfermeiro irá se inserir. Por ser o enfermeiro o intelectual da equipe pode caber-lhe o domínio dos elementos teóricos sobre o trabalho, contudo, descolados da prática.
Pensamos que estas questões são específicas à condução dos conteúdos, mas entendemos que elas explicitam os direcionamentos gerais e legais que são dados ao ensino e, neste particular, pensamos ser necessário inserir nessa discussão as propostas para o ensino de enfermagem elaboradas nos anos 80 e 90 e as atuais diretrizes curriculares da Comissão de Especialistas da SESU/MEC.

A proposta contida no Parecer 314/94, em nossa avaliação, foi uma tentativa que apontava a superação daquela distância, desconsiderada no momento com a proposta de diretrizes curriculares. A proposta atual de diretrizes curriculares é de elaboração da Comissão de Especialistas do Ensino em Enfermagem, buscando adequar-se à LDB 9394/96. Ela mostra-se como um retrocesso à fragmentação do ensino que tínhamos com o Parecer 163/72.

Nessa nova proposta fica clara a volta às criticadas habilitações e o que nos chama atenção, nessas habilitações, é a formação do pesquisador ou do habilitado em pesquisa. No que concerne às discussões feitas por nós até então, viemos postulando que a produção do conhecimento acontece no trabalho e questionamos: Qual a vinculação da pesquisa com o trabalho quando o pesquisador for exclusivamente habilitado para a pesquisa? Como os problemas a serem pesquisados serão formulados, na perspectiva de quem não está envolvido com a prática assistencial? Cremos que haverá uma distância ainda maior entre aqueles que executam e aqueles que pensam o trabalho, exacerbando sobremaneira a distância entre teoria e prática.

A temática das diretrizes curriculares foi discutida no $51^{\circ}$ Congresso Brasileiro de Enfermagem; na Reunião Nacional dos Cursos e Escolas de Enfermagem, quando os educadores da enfermagem alertaram para o abandono das discussões coletivas realizadas nas décadas de 80 e 90 (ASSOCIAÇÃO BRASILEIRA DE ENFERMAGEM, 1999). Entendemos que a defesa dos pressupostos para a educação, construídos coletivamente nas décadas de 80 e 90, constitui-se em uma ação efetiva em direção a um ensino pautado na realidade, com conteúdos pertinentes à inserção do enfermeiro nas reais necessidades da maioria das pessoas.

\section{AS MUDANÇAS TECNOLÓGICAS, O PAPEL DA ESCOLA E AS ESPECIFICIDADES DO ENSINO DE ENFERMAGEM}

O estudo ainda apontou que existe uma distância entre o que se ensina na graduação e o que o enfermeiro encontra posteriormente, no que tange ao domínio de 
novas tecnologias, direcionando para a necessidade de dominar essas novas tecnologias na atuação diária, de forma a eliminar aquela defasagem.

Ilustramos a dissonância entre ensino e a incorporação de novas tecnologias, com a seguinte fala:

"(...) tinha uma enfermeira que se formou comigo ela tinha ido fazer curso numa localidade (...) ela aprendeu que tinha que tirar as pinças do germikil. Eu não tinha visto isso ainda, então ele (o médico) acabou assim humilhando muito pela situação que a faculdade não formava bem os profissionais. Que nós saíamos de lá cruas e que a gente não sabia desempenhar bem as funções. (...) Era um produto já usado, mas não ensinou isso na época. Se tivesse me orientado.(...)". EnA E6

Além desse descompasso das novas tecnologias, há ainda as mudanças no modo de assistir que acontecem primeiramente na prática assistencial e daí passam a definir as formas e conteúdos necessários para atenderem as novas necessidades impostas.

“(...) eu acho que a relação ainda está aquém, a gente não tá dando conta dentro do ensino de nível superior, pelas próprias mudanças politicas, administrativas, as questões sócio-econômicas que a sociedade tem passado. Eu acho que a formação não tá tendo pernas para acompanhar ou não tá dando conta de fundamentar esse profissional. (...) ele sai e quando ele chega na realidade a teoria que a gente passou na graduação não é a que ele encontra mais. Pela própria dinâmica, pelos problemas que a comunidade tá tendo, no sistema de saúde como um todo. (...)". EnD E9

As mudanças na prática assistencial, definindo o comportamento dos profissionais bem como apontando para a necessidade de alterações na sua formação, comportam duas implicações que nos parecem essenciais.

A primeira diz respeito à ação determinante das relações objetivas sobre a ação dos sujeitos, alertandonos que, especificamente, no caso do aparelho formador de enfermagem, o movimento dá-se no sentido da prática assistencial para a educação. Neste movimento há um esforço de adaptação ao espaço em que acontece a prática assistencial da enfermagem, por parte do aparelho formador. Essa questão está diretamente relacionada ao movimento de produção do conhecimento que não ocorre exclusivamente na escola, e sim no interior das relações sociais, implicando naquele movimento de adaptação. A escola constitui-se num desses espaços, mas não é o mais importante deles, nesse conjunto de relações onde ocorre a produção e a distribuição do conhecimento (KUENZER,1991).
Por outro lado, e aí parece residir a importância de se ter clareza da primeira questão, aquele movimento de adaptação, por vezes, pode ser vivido sem nenhuma reflexão, constituindo-se num movimento de "adequação". Nesse ponto acreditamos residir o papel fundamental da "teoria", de possibilitar a reflexão no âmbito do aparelho formador, oferecendo subsídios para definirmos até que ponto, simplesmente adequar-se àquelas exigências do espaço prático, é um projeto para a maioria das pessoas. Reside aqui a necessidade de posicionamento de classe, tanto por parte dos docentes como dos enfermeiros inseridos no trabalho assistencial, definindo de que lado estamos e como devemos utilizar o espaço educacional formal para transformações mais incisivas. A partir somente desse espaço não se produz as transformações necessárias mas o mesmo comporta alguns meios para concretizá-las.

Apesar de produzido socialmente, o saber é apropriado privativamente, pois não está disponível a todas as pessoas. Sabemos que o avanço tecnológico acaba sendo apropriado pelos detentores dos meios de produção e assim a escola não é e nem poderia ser o local, por excelência, de produção do saber, com o fim de transportá-lo à prática, através dos profissionais nela formados. Segundo KUENZER (1991, p.23), A escola não é depositária do saber científico e tecnológico de ponta, dominado pelo capital; ela democratiza quando muito, alguns princípios teóricos e metodológicos que poderão, no exercício do trabalho, permitir essa apropriação.

No setor saúde, local da atuação do enfermeiro, o avanço tecnológico é evidente como também a diferenciada possibilidade de acesso. A referência de COHN (1999) a esse respeito, é bastante esclarecedora. Para a autora, trata-se de um setor.

crescentemente distante das reais necessidades de saúde da população brasileira - afirmam alguns especialistas da área que $80 \%$ dos problemas de saúde da população brasileira seriam passíveis de serem resolvidos pelo atendimento de primeira linha (rede básica de serviços de saúde: centros de saúde, ambulatórios, etc.); no entanto, criou-se no país uma infraestrutura de serviços altamente complexa, com alta densidade tecnológica, sem integração e hierarquização dos serviços de acordo com sua complexidade tecnológica. Como resultado, a população passa a ser atendida por serviços cuja lógica de acesso não responde à relação disponibilidade tecnológica/necessidade de atendimento, mas a necessidade de lucratividade do setor privado (COHN,1999, p.43). 
O modelo referido pela autora é centrado no atendimento médico individual-privado, financiado pelo Estado, ao qual a grande maioria da população não tem nenhum acesso, restando-lhe os poucos espaços públicos que não oferecem esse tipo de assistência (ibidem). Constatamos que o avanço tecnológico presente no setor saúde, não é de acesso coletivo e não é capaz de contribuir para elevar o nível da saúde das pessoas em função de sua vinculação ao capital privado, o que, a nosso ver, precisa ser considerado quando pensamos na adequação da escola ao mercado de trabalho, no tocante ao domínio da tecnologia. Ou seja, a tecnologia de ponta não é repassada pelo ensino, em função da sua produção ocorrer, de forma mais intensa, no trabalho, fora da escola e é de propriedade privada. O mercado de trabalho em saúde incorpora a tecnologia mas é excludente. A quem atenderemos pautando-nos na lógica de atenção a esse mercado? Pensamos que a adequação irrestrita a esse mercado seletivo e excludente não pode constituir-se no projeto para a enfermagem. Porém, não podemos confundir tal proposição com o direcionamento do ensino apenas para os aspectos da assistência primária, hoje a mais evidente para os pobres. Na verdade, cumpre a socialização da atenção à saúde, em todos os níveis, à todas as pessoas, de forma igualitária. Da mesma forma, o ensino deve ser pautado em todas as dimensões da assistência, embora repassar a tecnologia de ponta seja, em nosso entendimento, nesse momento, uma atividade difícil de ser operacionalizada dadas aquelas discrepâncias entre a produção e reprodução do conhecimento que discutimos anteriormente.

\section{CONSIDERAÇÕES FINAIS}

Este estudo partiu das suposições de que a escola, onde dá-se o ensino de graduação em enfermagem, tem dificuldades em preparar o enfermeiro para enfrentar as exigências do mercado de trabalho. Retomando as questões que formulamos a respeito da relação entre o ensino e o mercado de trabalho, alertamos que é preciso ter cautela ao pensarmos nas reformulações do ensino quando a justificativa é a de que o mesmo não responde as necessidades do mercado de trabalho. O mercado de trabalho, no modo de produção capitalista, tem como finalidade última o lucro e, com certeza, produzir saúde, assim como educação, para a maioria das pessoas não se coaduna com os interesses desse mercado, se não implicar em lucro.

Vemos no setor saúde, a inversão entre aquilo que poderia atender à demanda da maioria das pessoas em benefício do avanço tecnológico, restrito a uma pequena parcela que pode custear ou comprar saúde.
Nestes termos a "saúde" entra no campo das mercadorias em que é possível sua compra e venda. Esse modelo é custeado pelo Estado que assume as medidas de caráter coletivo mas financia o setor privado responsável pelo atendimento médico individual com incorporação crescente de tecnologia, concentrando-se onde haja possibilidades de expansão sempre maior. Desta forma, é preciso ter claro, se é exclusivamente para esse mercado que pensamos formar o profissional enfermeiro. Por outro lado, não se pode ignorá-lo, pois é o espaço onde o enfermeiro irá inserir-se. Como superar esses limites do lado da educação e os limites inerentes ao mercado de trabalho?

Em nosso entendimento, a formação do enfermeiro precisa abandonar a postura de neutralidade que a perpassa até o momento, seja nos conteúdos específicos das disciplinas ou dos currículos. Abandonar essa neutralidade significa assumir de que lado estamos e, pelas condições concretas a que somos expostos, enquanto trabalhadores, parece que o nosso lado não pode ser outro senão o da classe trabalhadora, a classe que não tem acesso à saúde da forma como ela se encontra organizada atualmente. Nossa condição de trabalhadores ficou explícita quando nos defrontamos com os valores salariais e a nossa jornada de trabalho. Embora isso seja evidente não podemos perder de vista a vinculação, consciente ou não, dos enfermeiros à classe dos detentores do capital, dadas as determinações que discutimos. Ou seja, o papel de ponte, assumido pelo enfermeiro enquanto "gerente", entre os donos das instituições e os trabalhadores manuais representados por auxiliares, técnicos, atendentes, agentes de saúde.

Não estamos defendendo que apenas essa mudança de postura do lado da formação, seja capaz de reverter aquele quadro, dado que a educação/escola faz parte dos aparelhos superestruturais e não pode por si promover mudanças ou alterar as relações sociais. Por outro lado, é preciso compreender que existem sim, na escola, lacunas, fendas, que podem ser utilizadas na construção de um modelo diferente de ensino e de assistência tendo claro, entretanto, as limitações desse espaço. Adequar-se simplesmente ao mercado de trabalho na perspectiva de aceitação é abdicar definitivamente da possibilidade de mediação da escola na transformação da sociedade. É nesse sentido que a mudança de postura é essencial, pois só assim poderemos buscar e construir essas possibilidades.

No que tange à adequação tendo como ponto de referência as mudanças tecnológicas, avaliamos que a explicação relativa ao movimento de produção do conhecimento é bastante elucidativa. Nesse sentido, é preciso atentar para o fato de que, se a produção do conhecimento e, conseqüentemente, as mudanças na tecnologia, acontecem primeiro no trabalho no "seu acontecendo", afirmar que a escola não consegue 
adequar-se ao mercado de trabalho em função de que não repassa a tecnologia de ponta, e buscar tal adequação através de mudanças no ensino, terá como resultado o balanço negativo da educação como não sendo capaz de acompanhar tais alterações. Chamamos a atenção para que não se incentive esse balanço negativo pois, como vimos, existe uma diferença entre aquilo que é produzido no trabalho e o que é repassado pelo ensino.

\section{NURSING CARE THEORY AND PRACTICE: TEACHING AND THE LABOR MARKET}

This study identifies how faculty nurses and clinical nurses experience the relationship between teaching and the labor market in Nursing. Data were collected by means of interviews and documentary analysis. Methodological and content categories were utilized for analysis. It became evident that teaching is far from the clinical practice and that it is based on contents which do not have correspondents; there is a phase displacement between what is taught in undergraduation and the incorporation of new technologies, practices and knowledge. Action towards reflections about nursing teaching in order to approach it to clinical work areas is pointed out.

KEY WORDS: nursing, teaching, work

\section{TEORÍA Y PRÁCTICA ASISTENCIAL EN ENFERMERÍA: LA ENSEÑANZA Y EL MERCADO DE TRABAJO}

El estudio identifica como los enfermeros docentes y asistenciales viven la relación entre la enseñanza y el mercado de trabajo en enfermería. La recolección de los datos se hizo mediante la realización de entrevistas y análisis de documentos. Para el análisis se utilizaron categorías metodológicas y de contenido. Se evidenció que la enseñanza está distante de la práctica asistencial y basada en contenidos que no corresponden con la práctica. Existe una diferencia entre lo que se enseña en el pregrado y la incorporación de nuevas tecnologías, prácticas y saberes. Se resalta la necesidad de retomar las reflexiones sobre la enseñanza en enfermería con el fin de aproximar el espacio de la enseñanza y el trabajo asistencial.

TÉRMINOS CLAVES: enfermería, enseñanza, trabajo

\section{REFERÊNCIAS BIBLIOGRÁFICAS}

01. ALMEIDA, M.C.P.; ROCHA, J.S.Y. O saber de enfermagem e sua dimensão prática. 2. ed. São Paulo: Cortez, 1989.

02. ASSOCIAÇÃO BRASILEIRA DE ENFERMAGEM. Documento final da reunião nacional de cursos e escolas de graduação em enfermagem. Florianópolis, 1999. /mimeografado/

03. CARVALHO, A.C. Orientação e ensino de estudantes de enfermagem no campo clínico. São Paulo, 1972. 150p. Tese (Doutorado) Escola de Enfermagem, Universidade de São Paulo.

04. COHN, A. A saúde na previdência social e na seguridade social: antigos estigmas e novos desafios. In: COHN, A.; ELIAS, P.E. Saúde no Brasil: políticas e organização dos serviços. 3. ed. São Paulo: Cortez/CEDEC, 1999. p. 13-57.
05. CURY, C.R.J. Educação e contradição: elementos metodológicos para uma teoria crítica do fenômeno educativo. 3. ed. São Paulo: Cortez/ Autores Associados, 1987.

06. Friggotto, G. A produtividade da escola improdutiva. 5. ed. São Paulo: Cortez, 1999.

07. KUENZER, A.Z. Educação e trabalho no Brasil o estado da questão. Brasília: Instituto Nacional de Estudos e Pesquisas Educacionais, 1991.

08. _ Desafios teórico-metodológicos da relação trabalho-educação e o papel social da escola. In: FRIGGOTTO, G. (Org.). Educação e crise do trabalho: perspectivas de final de século. Petrópolis: Vozes, 1998. 